\title{
Passive measurement of nitrogen oxides to assess traffic- related pollutant exposure for the East Bay Children's Respiratory Health Study
}

\author{
Brett C. Singer ${ }^{\mathrm{a}, 1}$, Alfred T. Hodgson ${ }^{\mathrm{b}}$, TOShifumi HotChi ${ }^{\mathrm{b}}$, AND JANICE J. \\ $\mathrm{KIM}^{\mathrm{c}}$ \\ ${ }^{\mathrm{a}}$ Atmospheric Sciences Department and ${ }^{\mathrm{b}}$ Indoor Environment Department, Environmental \\ Energy Technologies Division, Lawrence Berkeley National Laboratory, Berkeley, CA, USA \\ ${ }^{\mathrm{c}}$ Air Toxicology and Epidemiology Section, Office of Environmental Health Hazard Assessment, \\ California Environmental Protection Agency, Oakland, CA, USA
}

\section{Abstract}

The East Bay Children's Respiratory Health Study is examining associations between trafficrelated pollutant exposures and respiratory health among children who reside and attend schools at varied proximity to northern California freeways. Chronic exposures are being inferred from outdoor pollutant concentrations at neighborhood schools. This paper reports primarily weeklong integrated $\mathrm{NO}_{2}$ and $\mathrm{NO}_{\mathrm{X}}$ concentrations measured with passive samplers placed outside at ten elementary schools during 14 weeks in spring and 8 weeks in fall 2001. Measurements were also made outside selected student residences to examine spatial variability within three school neighborhoods. Regional concentrations of $\mathrm{NO}_{2}$ and $\mathrm{NO}_{\mathrm{X}}$ varied widely from week to week. School site data were normalized to measurements at a nearby regional monitoring station to facilitate analysis of relative pollutant exposures at the neighborhood schools. Normalized

\footnotetext{
${ }^{1}$ Corresponding author:

Address: Lawrence Berkeley National Laboratory, MS 51-208, Berkeley, CA 94720, USA. Tel.: +1-510-486-4779. Fax: +1-510-486-5928. E-mail: BCSinger@lbl.gov
} 
concentrations were consistent at each school throughout the study. Schools located upwind or far downwind of freeways were generally indistinguishable from one another and regional pollution levels. For school and neighborhood sites within $350 \mathrm{~m}$ downwind of a freeway, concentrations increased with decreasing downwind distance. The highest normalized concentrations occurred at a school located directly adjacent to a major freeway and a shopping center. In this case, normalized $\mathrm{NO}_{2}$ and $\mathrm{NO}_{\mathrm{X}}$ were $\sim 60 \%$ and $\sim 100 \%$ higher than regional background levels. At three schools within 130-230 m downwind of a freeway, normalized $\mathrm{NO}_{2}$ and $\mathrm{NO}_{\mathrm{X}}$ were $\sim 20-30 \%$ and $\sim 50-80 \%$ higher than regional levels. Validation testing of the passive samplers indicated precision of better than $5 \%$ for both $\mathrm{NO}_{2}$ and $\mathrm{NO}_{\mathrm{X}}$ when samplers were deployed outside for one-week periods. Passive sampler results agreed with co-located chemiluminescence measurements to within $8 \%$ for $\mathrm{NO}_{2}$ and $3 \%$ for $\mathrm{NO}_{\mathrm{X}}$.

\section{Key Words}

Nitrogen dioxide, Schools, Freeways, Passive sampler

\section{Introduction}

Motor vehicle emissions are a major contributor to urban and regional air pollution, and thus represent a public health concern on these spatial scales. A growing body of research has found that vehicle-related pollution also has localized impacts on pollutant concentrations and health. Epidemiological studies have reported increased respiratory symptoms and/or decreased lung function among subjects living closer to busy roads (e.g., Nitta et al., 1993; Pershagen et al., 1995; Brunekreef et al., 1997; van Vliet et al., 1997). This literature recently has been reviewed (Delfino, 2002).

The effect of large traffic sources on local pollutant concentrations was reported two decades ago by Rodes and Holland (1981), who showed that nitrogen oxides $\left(\mathrm{NO}_{\mathrm{X}}\right)$ concentrations decayed exponentially with distance downwind from a Los Angeles freeway. Recent studies in Europe and Japan have investigated associations between pollutant concentrations and an array of traffic metrics including major roadway proximity, total traffic intensity, truck traffic, and the 
fraction of time a given site is downwind from the roadway (e.g., Nakai et al., 1995; Janssen et al., 1997; Roorda-Knape et al., 1998; Fischer et al., 2000; Kingham et al., 2000; Lebret et al., 2000; Janssen et al., 2001). In the most extensive of these, Janssen et al. (2001) measured $\mathrm{PM}_{2.5}$ mass and filter reflectance (British black smoke, or “soot”), benzene, and nitrogen dioxide $\left(\mathrm{NO}_{2}\right)$ inside and outside at 24 schools within $400 \mathrm{~m}$ of major roadways in the Netherlands. They found $\mathrm{PM}_{2.5}$ and soot increased significantly with truck traffic and roadway proximity, while indoor $\mathrm{NO}_{2}$ was significantly positively correlated with car traffic. Both indoor and outdoor $\mathrm{NO}_{2}$ increased with percent of time downwind. In another Dutch study, Roorda-Knape et al. (1998) reported similar results: outdoor black smoke and $\mathrm{NO}_{2}$ decreased with roadway distance; indoor black smoke correlated to percent of time downwind and truck density; and indoor $\mathrm{NO}_{2}$ correlated to time downwind, total traffic and roadway distance. However, no gradients were seen for $\mathrm{PM}_{10}, \mathrm{PM}_{2.5}$ or benzene as a function of roadway distance. Fischer et al. (2000) reported elevated benzene, total volatile organic compound (VOC) and polycyclic aromatic hydrocarbon (PAH) concentrations outside homes on high-traffic streets relative to homes on low-traffic streets in Amsterdam. Nakai et al. (1995) reported consistently elevated outdoor $\mathrm{NO}_{2}$ concentrations at homes located 0-20 m and 20-150 m from Tokyo roadways with high truck traffic, compared to reference sites. In Huddersfield, England, Kingham et al. (2000) found no significant pollutant concentration differences in traffic pollutants (e.g., benzene, PAH, and mass and absorbance of $\mathrm{PM}_{10}$ and $\mathrm{PM}_{2.5}$ ) between homes $<50 \mathrm{~m}$ compared with those $>50 \mathrm{~m}$ from roadways carrying peak traffic of 1200-2500 vehicles per hour.

In several of these studies (Roorda-Knape et al., 1998; Lebret et al., 2000; Janssen et al., 2001) $\mathrm{NO}_{2}$ was measured with a passive sampling technique first described by Palmes et al. (1976). This method combines diffusive sampling through an open tube with collection on metal screens coated with triethanolamine (TEA). Yanigasawa and Nishimura (1982) demonstrated the sampling of nitrogen oxide (NO) onto layered glass-fiber filters containing chromium trioxide to oxidize $\mathrm{NO}$ to $\mathrm{NO}_{2}$. Ogawa \& Co. markets TEA-based sampling pads for $\mathrm{NO}_{2}$ and pads for $\mathrm{NO}_{\mathrm{X}}$ that use a proprietary solution to oxidize $\mathrm{NO}$ to $\mathrm{NO}_{2}$ with reportedly less sensitivity to humidity effects. Spicer et al. (2001) have shown TEA-based samplers can accurately measure $\mathrm{NO}_{2}$, but 
are subject to a positive artifact as they collect nitrous acid (HONO) at rates similar to $\mathrm{NO}_{2}$. The interference may be important for indoor applications but is of less concern outdoors where ambient concentrations of $\mathrm{HONO}$ are typically much lower than $\mathrm{NO}_{2}$ (Zellweger et al., 1999).

The European and Japanese results referenced above may not be directly relevant to the U.S. because of differences in vehicle fleets, roadway types, residences, and land use patterns. California's Office of Environmental Health Hazard Assessment (OEHHA) initiated the East Bay Children’s Respiratory Health Study to examine traffic-related pollutant exposures and respiratory health among elementary school children who reside and attend schools at varying downwind distances from major northern California freeways (Kim et al., 2002). The study included pollutant concentration measurements and questionnaires about respiratory symptoms. This paper presents results of $\mathrm{NO}_{2}$ and $\mathrm{NO}_{\mathrm{X}}$ measurements made outside at ten schools and in several neighborhoods along with a series of validation tests of the outdoor $\mathrm{NO}_{2}$ and $\mathrm{NO}_{\mathrm{X}}$ passive sampling method.

\section{Methods}

\subsection{Study Design}

The East Bay Respiratory Health Study was designed around neighborhood elementary schools in the Eastern San Francisco Bay area of Northern California. Ten schools with similar socioeconomic demographics were selected to represent locations either upwind, or at varying downwind distances from three major East Bay freeways: California-92 (CA-92), Interstate-880 (I-880) and I-580. Schools identified as upwind or far downwind in Table 1 were not within 350 m of large roads (annual average daily traffic of $>25,000$ vehicles per day). A subset of students from each school was recruited for the health study. Most participating children resided in the neighborhood around their school. Exposures to traffic related pollutants were estimated by measuring outdoor pollutant concentrations at the schools. Carbon monoxide, fine particle mass, black carbon, VOCs, $\mathrm{NO}_{2}$ and $\mathrm{NO}_{\mathrm{X}}$ were measured during the spring and fall 2001 semesters. A supplemental study was conducted in spring 2002 to investigate relationships between $\mathrm{NO}_{\mathrm{X}}$ concentrations measured at three schools and surrounding neighborhoods. 


\subsection{Measurement of $\mathrm{NO}_{2}$ and $\mathrm{NO}_{X}$}

$\mathrm{NO}_{2}$ and $\mathrm{NO}_{\mathrm{X}}$ were collected over weeklong periods using pre-coated 14.5-mm pads (P/Ns PS-114 and PS-124, Ogawa \& Co.) deployed in personal sampler bodies (P/N P-100, Ogawa \& Co.). Sampling and analysis was performed according to manufacturer protocols (Ogawa, 1998). Pads were loaded into samplers several hours before deployment and stored in airtight cups for transport to/from sampling sites. Samplers were deployed in several described configurations. Field blanks were transported with samples and momentarily exposed. Following collection, samplers were refrigerated until analyzed (except during shipment).

Samples collected during weeks 1-14 of spring 2001 were shipped overnight to Ogawa USA, which forwarded the samples analysis: to Research Triangle Institute, NC in week 1 and Ogawa Japan in weeks 2-14. Field and laboratory blanks were sent with each sample batch. Samples and blanks were sent blind using a random coding system. Laboratories reported the mass of $\mathrm{NO}_{2}$ or $\mathrm{NO}_{\mathrm{X}}$ for each pad. A sample level mass was reported for one laboratory blank for weeks 5 and 7, indicating possible contamination or error. However, reported mass levels for all other samples from these weeks were consistent with prevailing trends observed throughout the study, so the data were retained. Several inconsistencies appeared in reported $\mathrm{NO}_{\mathrm{X}}$ masses for samples and blanks from week 2, suggesting a possible mix-up of sample vials or pads. As a precaution, all data from week 2 were excluded. Week 10 data for $\mathrm{NO}_{2}$ and $\mathrm{NO}_{\mathrm{X}}$ were excluded because of a mix-up related to identity codes.

Samples collected during fall 2001 monitoring, during validation experiments at the regional monitoring station (see next sub-section), and during the neighborhood study were analyzed at LBNL according to manufacturer protocols. A five-point calibration line was calculated at the start and checked at the end of each analysis session. Collected mass was converted to airborne concentration using the manufacturer's temperature and humidity dependency equations.

\subsection{Passive Sampler Validation}

Samplers were validated for both precision and accuracy. Precision was determined by collecting replicate samples for internal analysis. Three or more replicate samples were collected 
on 8 occasions and pairs were collected 17 times (72 total samples). These included 14 events during fall monitoring, 7 at the regional station and 4 during the neighborhood study. For each event, a relative deviation was calculated by dividing either the absolute difference between paired samples or the standard deviation calculated from 3 or more replicate samplers by the mean. Duplicate samples were collected on 6 occasions for external laboratories.

Accuracy was evaluated by comparing passive sampler results with online measurements at the Bay Area Air Quality Management District (BAAQMD) Fremont, CA station, just south of the study area. $\mathrm{NO}_{2}$ and $\mathrm{NO}$ are measured at the Fremont station by federal reference method (40 CFR Part 50, Appendix F) using a chemiluminescence analyzer (Thermo Environmental Instruments, Inc.). Passive samplers were deployed at Fremont during 7 weeklong periods in January through May 2002. Samplers were placed 1.5-2 m above the roof adjacent to the intake manifold for the station’s instruments. Samplers were deployed either inside a naturally ventilated (louvered) metal cabinet or clipped into holders for weather protection (see below). BAAQMD provided hourly concentrations of $\mathrm{NO}_{2}$ and NO. We estimated concentrations during the daily calibration interval of 0200-0400 by averaging values from 0100 and 0500 . Sampling period mean concentrations of $\mathrm{NO}_{2}, \mathrm{NO}$, and $\mathrm{NO}_{\mathrm{X}}\left(\mathrm{NO}_{2}+\mathrm{NO}\right)$ were compared to passive sampler results.

Limits of detection (LODs) were calculated as 3 times the standard deviations of absorbance of lab blanks measured in 8 analysis batches at LBNL ( $\mathrm{n}=3$ per analysis).

\subsection{Meteorological Data}

Meteorological data were obtained from the Western Regional Climate Center in Reno, NV for the June 2000 through May 2002 period. The data include hourly wind speed, wind direction and temperature measured at Oakland International and Hayward Executive airports, sited in the north and south regions of the study area. Relative humidity and temperature were measured during each weekly sampling period at the schools using RH/temperature data loggers (Model HOBO H8 Pro, Onset Computer Corp.). Temperature data were provided by BAAQMD for sampler validation periods. 


\subsection{School Sites}

Table 1 summarizes information about major traffic sources near the schools. Schools were arbitrarily assigned the numbers 1-10. They are displayed in tables and figures by their orientation and proximity to freeways. The predominant wind direction in the East Bay is from the SW-W or $\sim 225-270^{\circ}$ from North (Figure 1).

We selected schools at varying upwind or downwind distances from freeways. School and residential sampling locations were marked on a California State Automobile Association map (1:26400) and recorded using a global positioning system (Garmin GPS II). Distances and bearings to the nearest freeways were estimated by scaled map measurements and also calculated using geographic information system software (ArcView 3.2, ESRI, Redlands CA), yielding basically consistent results; an aerial photo was used to resolve a single discrepancy (distance from school 2 to CA-92). A measurement wheel was used to more precisely determine the distance from school 10 and 5 sampling sites to I-880. For schools 10, 5, 9, and 2, reported distances are from the monitoring sites to the freeway edge. At these sites the school grounds extended tens of meters closer to, and farther from the freeway. Average daily traffic counts were provided by the California Department of Transportation.

Pollutant monitoring equipment was placed inside metal cabinets $(90 \mathrm{~cm}$ x $45 \mathrm{~cm}$ x $180 \mathrm{~cm}$ high) sited at each school based on the following criteria: (a) centrally located in relation to classrooms and play areas; (b) >50 m from large parking lots, bus stops, student pickup areas, and loading docks; (c) unobtrusive to students and school staff; (d) availability of structure or fence to fasten cabinet for seismic and theft security; (e) adequate air circulation; (f) weather protection; (g) out of sight to passers-by.

Passive samplers were initially deployed by clipping them intermediately between cabinet tops and sun/rain shields $10 \mathrm{~cm}$ above (weeks 1-3). During week 1, samplers were placed both inside and outside of cabinets to test their equivalence. Samplers were placed inside cabinets on week 4 and subsequently.

Monitoring at the schools occurred over 14 weeks in spring 2001, 8 weeks in fall 2001 and 2 
weeks in spring 2002 (Table 2). Samplers were deployed predominantly over 1-week periods, with two 2-week sampling periods in spring 2001. Valid data are reported for 20 of 22 sampling periods. Samples from weeks 2 and 10 were invalidated as noted. Sampling at school 10 started on week 3 due to delay in site approval. Tampering and theft resulted in loss of several samples. Samplers were deployed on Wednesday afternoons in conjunction with early class dismissal.

\subsection{Neighborhood Sites}

The neighborhood study included school 6 (far downwind), school 3 (close but upwind) and school 5 (close and downwind of I-880). The goal was to measure concentrations outdoors at residences around the area where children from the three schools lived. Households were recruited through three mailings sent to all families participating in the Health Study; a video store gift-card was offered as incentive. We received 18 responses from school 6 families and 25 responses from families with children in schools 3 and 5 (slightly overlapping neighborhoods). The locations of their residences were compared to those of all participating families from the three schools. Two of the respondents from school 6 lived outside of the neighborhood and were excluded. All respondents from schools 3 and 5 were included. Another school was added as a supplemental sampling site to improve coverage of the school 5 neighborhood.

Sampling occurred outside 16 residences near school 6 during the first week and outside 25 residences and supplemental site near schools 3 and 5 during the second week. Sampling in duplicate occurred at the 10 schools and the Fremont station during both weeks. Samplers were deployed first to Fremont then to the schools then to the residences over $\sim 6$ h. Samplers were collected in the same order over $\sim 4$ hours.

Samplers were deployed clipped onto L-brackets mounted inside inverted 3” PVC plastic plumbing caps for weather protection. The housings were fastened to tree limbs, fences, or freestanding wooden stakes 1-2 m above ground, as far as possible from streets and driveways. 


\section{Results}

\subsection{Validation of Passive Samplers}

Passive samplers performed consistently and precisely for both $\mathrm{NO}_{2}$ and $\mathrm{NO}_{\mathrm{X}}$ (Table 3). Mean relative deviations from 25 co-location events indicate measurement precision better than $5 \%$ for $\mathrm{NO}_{2}$ and $\mathrm{NO}_{\mathrm{X}}$ and better than $10 \%$ for $\mathrm{NO}\left(\mathrm{NO}_{\mathrm{X}}-\mathrm{NO}_{2}\right)$. Relative deviation was largely independent of concentration. For individual events, relative deviations averaged $<5 \%$ for both $\mathrm{NO}_{2}$ and $\mathrm{NO}_{\mathrm{X}}$ across a wide range of ambient concentrations. Good overall precision was obtained for NO despite the effect of several outliers. Of the 25 events, the NO relative deviation was $<20 \%$ on 23 occasions and $<10 \%$ on 19 occasions. Co-located samplers analyzed by external laboratories were in close agreement ( $<5 \%$ deviation) for both $\mathrm{NO}_{2}$ and $\mathrm{NO}_{\mathrm{X}}$ for 4 of 6 events; deviations of 12 and 18\% ( $\left.\mathrm{NO}_{2}\right)$, and 11 and 34\% ( $\left.\mathrm{NO}_{\mathrm{X}}\right)$ occurred for the other two events. These external results are not included in Table 3.

Equivalence of results from different laboratories was evaluated by deploying two sets of samplers (including field blanks and one duplicate per set) at all 10 schools during the third week of monitoring in fall 2001 (week 17). One set was sent to Ogawa \& Co., Japan and the other was analyzed at LBNL. The results for $\mathrm{NO}_{2}$ agreed to within $0.2 \pm 1.5 \mathrm{ppb}$ (mean $\pm \mathrm{SD}, \mathrm{n}=10$ ) but the Ogawa results were higher by $3.5 \pm 1.5$ ppb for $\mathrm{NO}_{\mathrm{X}}$ (concentration range 36-93 ppb based on LBNL analysis). This deviation was consistent with the lower $\mathrm{NO}_{\mathrm{X}}$ blank values reported by Ogawa compared to those obtained consistently by LBNL. The cause of the blank discrepancy could not be determined. Fitting the data with regression lines through zero gave slopes of 1.0 for $\mathrm{NO}_{2}\left(\mathrm{R}^{2}=0.86\right)$ and 0.95 for $\mathrm{NO}_{\mathrm{X}}\left(\mathrm{R}^{2}>0.99\right)$.

Passive samplers were accurate in comparison to the reference chemiluminescence method. Results are indicated separately in Figure 2 for samplers deployed inside the metal cabinet and those deployed outside with protective caps at the Fremont station. Each point represents the average of 1-3 co-located samplers ( $\mathrm{n}=27$ total samples for each pollutant). $\mathrm{NO}_{2}$ and $\mathrm{NO}_{\mathrm{X}}$ results are plotted together and combined in the regression analysis because they depend on similar collection and chemical analysis processes. Passive sampler results were highly correlated with 
chemiluminescence measurements with $\mathrm{r}^{2}=0.98$ for a line through zero with slope $=0.95$. Linear regressions also were calculated separately for each compound. Best-fit regression lines had positive intercepts of 3-4 ppb, but similar coefficients were obtained for regressions forced through zero. The slopes of the zero-intercept regressions were 0.92 for $\mathrm{NO}_{2}\left(\mathrm{R}^{2}=0.94\right)$ and 0.97 for $\mathrm{NO}_{\mathrm{X}}\left(\mathrm{R}^{2}=0.98\right)$. Paired t-tests yielded $\mathrm{p}<0.01$ for $\mathrm{NO}_{2}$ and $\mathrm{p}=0.09$ for $\mathrm{NO}_{\mathrm{X}}$.

Samplers deployed in a cabinet at the Fremont station yielded slightly lower concentrations for $\mathrm{NO}_{2}$ and $\mathrm{NO}_{\mathrm{X}}$ compared to those deployed outside under plastic caps. Mean cabinet versus cap deployment ratios were $0.97 \pm 0.03$ for $\mathrm{NO}_{2}(\mathrm{p}=0.16)$ and $0.94 \pm 0.05$ for $\mathrm{NO}_{\mathrm{X}}(\mathrm{p}=0.05)$. However, simultaneous inside/outside cabinet deployments during week 1 of spring 2001 monitoring produced the opposite result. Samplers deployed inside cabinets yielded slightly higher concentrations than those clipped outside. The ratio of inside to outside of cabinet was $1.05 \pm 0.06$ for $\mathrm{NO}_{2}(\mathrm{p}=0.03)$ and $1.08 \pm 0.05$ for $\mathrm{NO}_{\mathrm{X}}(\mathrm{p}<0.01)$.

Limits of detection were $0.2 \mathrm{ppb} \mathrm{NO}_{2}$ and $0.4 \mathrm{ppb} \mathrm{NO}_{\mathrm{X}}$ for one-week sampler deployment.

\subsection{Wind Direction}

Composite diurnal wind profiles for each calendar month were calculated from two years of wind data spanning June 2000 through May 2002. The profiles shown in Figure 1 reflect winds that winds were consistently from the west or southwest throughout the day during spring and summer (Apr-Aug). In fall and winter (Sep-Feb), overnight winds shifted to southerly then southeasterly but daytime winds were primarily from the southwest. Table 3 shows the wind was predominantly from the west or southwest through spring monitoring, but shifted to southerly $\left(180^{\circ}\right)$ at the end of fall 2001monitoring. Therefore, sites to the east or northeast of freeways were predominantly downwind from traffic emissions. Winds were consistently from the west during neighborhood sampling. Thus, the participating residences near school 5 were downwind and the residences near school 3 were upwind of I-880 during week 24.

\subsection{Traffic Sources near Schools}

Table 1 shows that three schools (5, 9, and 10) were located within $200 \mathrm{~m}$ in the predominant downwind direction of I-880 with an annual average daily traffic (AADT) of about 200,000 
vehicles per day. A large fraction of the students at these schools lived nearby and downwind from I-880. School 2 and many associated students resided downwind from CA-92 with an AADT of 90,000. School 2 and its neighborhood also are located close and generally upwind from I-880 but were downwind from I-880 during some winter periods.

\section{4. $\mathrm{NO}_{2}$ and $\mathrm{NO}_{X}$ Concentrations at Schools}

School site monitoring results are summarized in Table 4 and Figures 3-4. All individual $\mathrm{NO}_{2}$ concentrations measured at the schools were below the national standard of $53 \mathrm{ppb}$ annual average. Mean $\mathrm{NO}_{2}$ concentrations were less than half the standard at all but one school. $\mathrm{NO}_{2}$ at individual schools varied by $16-34 \%$ across sampling periods. $\mathrm{NO}_{\mathrm{X}}$ concentrations varied more widely over time. Sampling period mean $\mathrm{NO}_{\mathrm{X}}$ concentrations ranged over a factor of 2 , compared to a $\sim 50 \%$ difference between the highest and lowest $\mathrm{NO}_{2}$ values. $\mathrm{NO}_{\mathrm{X}}$ relative standard deviations at individual school sites were 23-45\%. Differences between the $\mathrm{NO}_{\mathrm{X}}$ and $\mathrm{NO}_{2}$ values indicate that $\mathrm{NO}$ was more abundant than $\mathrm{NO}_{2}$ during many weeks.

For each sample period, concentrations at individual school sites were normalized to concentrations at the Fremont station. This enabled a robust analysis of relative $\mathrm{NO}_{2}$ and $\mathrm{NO}_{\mathrm{X}}$ levels among the schools using data from all monitoring periods. Normalized concentrations are summarized in Table 4 and displayed in Figure 5. The statistical significance of differences of mean normalized concentrations among the schools was determined by one-way analysis of variance. The Fisher Protected Least Significant Difference test was used to compare the individual means (Statview software, version 5.0.1, SAS Institute). Table 4 shows the schools with normalized mean concentrations different from one another at $\mathrm{p}<0.05$.

The schools can be roughly divided into three exposure levels based on this analysis. In general, $\mathrm{NO}_{2}$ normalized concentrations at schools 1, 3, 4, 6 and 7 were not statistically distinguishable from one another or from the Fremont station results. These schools were either upwind or far downwind from any freeway. The effects of a nearby freeway were apparent at the other schools. Concentrations of $\mathrm{NO}_{2}$ were elevated by $~ 15-20 \%$ at schools 8 and 2, and by $\sim 35 \%$ at schools 5 and 9, relative to the Fremont station. Normalized $\mathrm{NO}_{2}$ concentrations at 
school 10 were significantly higher than at all other schools, and $\sim 60 \%$ above the mean Fremont value. Normalized $\mathrm{NO}_{\mathrm{X}}$ concentrations showed a similar pattern. $\mathrm{NO}_{\mathrm{X}}$ concentrations were lowest and statistically indistinguishable at schools 7, 6, 4, and 1 (in order). $\mathrm{NO}_{\mathrm{X}}$ was elevated at school 8 relative to school 7, and at school 3 relative to schools 6 and 7. Differences of 50\% or more occurred for schools 2, 5 and 9 relative to Fremont. $\mathrm{NO}_{\mathrm{X}}$ concentrations at school 10 were about twice those at Fremont and were statistically higher than those at 8 other schools.

\subsection{Neighborhood Study Results}

Figure 6 displays the concentrations measured outside residences of students attending schools 3, 5, and 6. Summary statistics are presented in Table 5. Consistent with measurements at the school sites throughout the study, mean and median concentrations of both $\mathrm{NO}_{2}$ and $\mathrm{NO}_{\mathrm{X}}$ were highest in the neighborhood surrounding school 5. Higher $\mathrm{NO}_{2}$ and $\mathrm{NO}_{\mathrm{X}}$ concentrations were measured at residences in the neighborhood around school 6, which is downwind but far from the freeway, than were measured at residences near school 3. This result contrasts with the statistically significantly lower $\mathrm{NO}_{\mathrm{X}}$ concentrations observed at school 6 relative to school 3.

For school 3, there was a high level of consistency between $\mathrm{NO}_{2}$ and $\mathrm{NO}_{\mathrm{X}}$ concentrations at the school site and the central tendency measures (mean and median) for its associated residences. For the school 6 neighborhood, school site $\mathrm{NO}_{2}$ and $\mathrm{NO}_{\mathrm{X}}$ values were lower than the residential central tendency values; but the differences were generally within 10-25\%. In contrast, $\mathrm{NO}_{2}$ and $\mathrm{NO}_{\mathrm{X}}$ concentrations at school 5 were higher than the respective central tendency measures for the associated residential sites by more than $30 \%$.

\section{Discussion}

The passive samplers used in this study yielded accurate and precise measurements of $\mathrm{NO}_{2}$ and $\mathrm{NO}_{\mathrm{X}}$ when deployed outdoors for a one-week interval. The samplers were deployed in a variety of locations and housings for weather protection. The capability to measure both $\mathrm{NO}_{2}$ and $\mathrm{NO}_{\mathrm{X}}$ is valuable for studies of traffic-related pollution, since near-source spatial patterns may differ between the species.

Absolute concentrations of $\mathrm{NO}_{2}$ and $\mathrm{NO}_{\mathrm{X}}$ measured at ten neighborhood elementary schools 
varied substantially from week to week, presumably because of variations in atmospheric mixing throughout the study region. Yet relative levels among the schools were consistent over the twoseason study, as indicated by the low standard errors of the mean normalized concentrations (Table 4.) Normalized $\mathrm{NO}_{2}$ and $\mathrm{NO}_{\mathrm{X}}$ are plotted in Figure 5 as a function of downwind distance to the nearest freeway along the predominant wind direction (from the W-SW). Concentrations of both $\mathrm{NO}_{2}$ and $\mathrm{NO}_{\mathrm{X}}$ were substantially and significantly elevated at the schools that were predominantly downwind and within a few hundred meters of either I-880 or CA-92. The highest normalized concentrations occurred at school 10, which is located $\sim 60 \mathrm{~m}$ from I-880 in the predominant downwind direction. This school also is located immediately to the north of a midsized shopping center parking lot. At this school, $\mathrm{NO}_{2}$ and $\mathrm{NO}_{\mathrm{X}}$ were $\sim 60 \%$ and $100 \%$ higher than the regional levels measured at the Fremont station and at schools far from freeways. Schools 5 and 9, located at predominantly downwind distances of 130 and $200 \mathrm{~m}$ respectively from I-880, experienced concentrations that were higher than regional levels by about 35\% for $\mathrm{NO}_{2}$ and $60-80 \%$ for $\mathrm{NO}_{\mathrm{X}}$. Near-source effects of the freeway were somewhat higher in the spring when the wind blew from west to east (i.e. directly from the freeway to the schools) almost uniformly throughout the day, and somewhat lower in the fall, when overnight winds were from the southwest or south (Figure 1). These results provide quantitative data on elevated $\mathrm{NO}_{2}$ and $\mathrm{NO}_{\mathrm{X}}$ concentrations close and downwind from major freeways.

The relative traffic-related pollutant exposures encountered by children while they attended school may have differed from this pattern if indoor-outdoor pollutant ratios differed consistently among schools. Indoor/outdoor ratios for $\mathrm{NO}_{2}$ and $\mathrm{NO}_{\mathrm{X}}$ are determined by penetration factors, surface losses, air exchange rates, and indoor sources (unlikely at schools). Ratios can vary by season and day at each school and by classroom, e.g. from differential use of mechanical versus natural ventilation. This important issue was not addressed in this study.

This study also did not attempt to quantify exposures associated with boarding and riding of diesel-powered school buses. The potential effect of school bus activity on school site samples cannot be ruled out. But since the samplers were sited away from bus loading zones, any effects captured should be representative of exposures throughout school grounds. 
Concentrations of $\mathrm{NO}_{2}$ and $\mathrm{NO}_{\mathrm{X}}$ measured outside residences in the vicinities of school 3 and 5 are plotted as a function of distance from I-880 in Figure 7, which includes measurements made during the same week at the six school sites within $1000 \mathrm{~m}$ of a freeway. As with the school sites, there was a clear trend of elevated $\mathrm{NO}_{2}$ and $\mathrm{NO}_{\mathrm{X}}$ at residences located within $\sim 350$ m downwind of I-880; the highest concentrations were seen at the shortest distances. Sites upwind and farther downwind generally had concentrations indicative of regional levels.

Neighborhood monitoring results demonstrated that school-based measurements were generally good indicators of $\mathrm{NO}_{2}$ and $\mathrm{NO}_{\mathrm{X}}$ levels at residences for neighborhoods that were either mostly upwind or far downwind from a freeway. However, both $\mathrm{NO}_{\mathrm{X}}$ and $\mathrm{NO}_{2}$ could be elevated at individual homes located on or closely downwind from high-traffic surface roads. Exposure evaluation for children attending schools closer and downwind from a freeway is more complicated as indicated by results for the school 5 neighborhood. Children who lived farther from the freeway than the school was from the freeway likely had overall exposures lower than indicated by the school site measurements. One approach to deal with this issue would be to estimate each individual child's overall exposure as a time-weighted sum of concentrations at school and at home. For this case, outdoor residential concentrations could be calculated as a function of distance from the freeway by fitting the data in Figure 6 to a mathematical equation. In fact, the data fit an equation of the form $\mathrm{C}(\mathrm{x})=\mathrm{K}_{1} \mathrm{x}^{\mathrm{K} 2}$ where $\mathrm{C}$ is the measured concentration at distance $\mathrm{x}$ from the freeway; the fits yield $\mathrm{R}^{2}=0.80$ for $\mathrm{NO}_{2}\left(\mathrm{~K}_{1}=128 ; \mathrm{K}_{2}=-0.356\right)$ and $\mathrm{R}^{2}=$ 0.76 for $\mathrm{NO}_{\mathrm{X}}\left(\mathrm{K}_{1}=376 ; \mathrm{K}_{2}=-0.468\right)$.

The school and neighborhood results indicated a similar localized impact of freeways on $\mathrm{NO}_{2}$ and $\mathrm{NO}_{\mathrm{X}}$ concentrations. In both studies, the magnitude of near-traffic effects appeared to be more pronounced for $\mathrm{NO}_{\mathrm{X}}$. We hypothesize that this results because $\mathrm{NO}_{\mathrm{X}}$ emissions from motor vehicles are almost entirely in the form of NO (Kirchstetter et al., 1996). NO reacts quickly with ozone to form $\mathrm{NO}_{2}$, but there may not always be enough ozone to titrate all of the emitted NO during the short period of transit between a freeway and a nearby site.

Results of this study are consistent with those from Europe and Japan that examined the effects of nearby roadways on $\mathrm{NO}_{2}$ concentrations. In both the school and neighborhood 
components, we measured elevated $\mathrm{NO}_{2}$ and $\mathrm{NO}_{\mathrm{X}}$ concentrations at sites within about $350 \mathrm{~m}$ downwind from large freeways. At schools and residences located within about $350 \mathrm{~m}$ upwind of these freeways, $\mathrm{NO}_{2}$ and $\mathrm{NO}_{\mathrm{X}}$ concentrations were similar to those measured at the regional air monitoring station and at school sites $>1000$ m downwind of the closest freeway.

\section{Acknowledgements}

The authors thank Svetlana Smorodinsky for managing the participant database and for GISmapping. We thank Bart Ostro, Michael Lipsett, and Lara Gundel for input on study design and equipment. Spanish translation was provided by Rosa Rodriguez-Flores and Alba Webb. Gary Zoppo (BAAQMD) helped with validation sampling and Avi Okin (BAAQMD) provided Fremont station data. This work was funded by Cal-EPA OEHHA through Contract 95-302. The U.S. Dept. of Energy provided additional support through Contract DE-AC03-76F00098.

\section{References}

Brunekreef B., Janssen N. A. H., de Hartog J., Harssema H., Knape M. and van Vliet P. Air pollution from truck traffic and lung function in children living near motorways. Epidemiology 1997: 8: 298-303.

Delfino R. J. Epidemiologic evidence for asthma and exposure to air toxics: Linkages between occupational, indoor, and community air pollution research [review]. Environ Health Perspect 2002: 110: 573-589.

Fischer P. H., Hoek G., van Reeuwijk H., Briggs D. J., Lebret E., van Wijnen J. H., Kingham S. and Elliott P. E. Traffic-related differences in outdoor and indoor concentrations of particles and volatile organic compounds in Amsterdam. Atmos Environ 2000: 34: 3713-3722.

Janssen N., Van Masom D. F. M., Van Der Jagt K., Harssema H. and Hoek G. Mass concentration and elemental composition of airborne particulate matter at street and background locations. Atmos Environ 1997: 31: 1185-1193. 
Janssen N. A. H., van Vliet P. H. N., Aarts F., Harssema H. and Brunekreef B. Assessment of exposure to traffic related air pollution of children attending schools near motorways. Atmos Environ 2001: 35: 3875-3884.

Kim, J. J., Smorodinsky S., Ostro B., Lipsett M., Singer B.C. and Hogdson A.T. Traffic-Related Air Pollution and Respiratory Health: The East Bay Children's Respiratory Health Study. Epidemiology 2002: 13: (Supplement 4): S100.

Kingham S., Briggs D., Elliott P., Fischer P. and Lebret E. Spatial variations in the concentrations of traffic-related pollutants in indoor and outdoor air in Huddersfield, England. Atmos Environ 2000: 34: 905-916.

Kirchstetter T. W., Singer B. C., Harley R. A., Kendall G. R. and Chan W. Impact of oxygenated gasoline use on California light-duty vehicle emissions. Environ Sci Technol 1996: 30: 661670.

Lebret E., Briggs D., van Reeuwijk H., Fischer P., Smallbone K., Harssema H., Kriz B., Gorynski P. and Elliott P. Small area variations in ambient $\mathrm{NO}_{2}$ concentrations in four european areas. Atmos Environ 2000: 34: 177-185.

Nakai S., Nitta H. and Maeda K. Respiratory health associated with exposure to automobile exhaust. 2. Personal $\mathrm{NO}_{2}$ exposure levels according to distance from the roadside. $J$ Expos Anal Environ Epidem 1995: 5: 125-136.

Nitta H., Sato T., Nakai S., Maeda K., Aoki S. and Ono M. Respiratory health associated with exposure to automobile exhaust. 1. Results of cross-sectional studies in 1979, 1982, and 1983. Arch Environ Health 1993: 48: 53-58.

Ogawa, \& Co. $\mathrm{NO}, \mathrm{NO}_{2}, \mathrm{NO}_{\mathrm{X}}$ and $\mathrm{SO}_{2}$ sampling protocol using the ogawa sampler. Ogawa \& Co, 1998. Accessed at www.ogawausa.com in 2001.

Palmes E. D., Gunnison A. F., Dimattio J. and Tomczyk C. Personal sampler for nitrogen dioxide. Amer Industr Hyg Assoc J 1976: 37: 570-577.

Pershagen G., Rylander E., Norberg S., Eriksson M. and Nordvall S. L. Air pollution involving nitrogen dioxide exposure and wheezing bronchitis in children. Int J Epidemiol 1995: 24: 1147-1153. 
Rodes C. E. and Holland D. M. Variations of NO, $\mathrm{NO}_{2}$, and $\mathrm{O}_{3}$ concentrations downwind of a Los Angeles freeway. Atmos Environ 1981: 15: 243-250.

Roorda-Knape M. C., Janssen N. A. H., de Hartog J. J., van Vliet P. H. N., Harssema H. and Brunekreef B. Air pollution from traffic in city districts near major motorways. Atmos Environ 1998: 32: 1921-1930.

Spicer C. W., Billick I. H. and Yanagisawa Y. Nitrous acid interference with passive $\mathrm{NO}_{2}$ measurement methods and the impact on indoor $\mathrm{NO}_{2}$ data. Indoor Air 2001: 11: 156-161.

van Vliet P., Knape M., de Hartog J., Janssen N., Harssema H. and Brunekreef B. Motor vehicle exhaust and chronic respiratory symptoms in children living near freeways. Environ Res 1997: 74: 122-132.

Yanagisawa Y. and Nishimura H. A badge-type personal sampler for measurement of personal exposure to $\mathrm{NO}_{2}$ and NO in ambient air. Environ Int 1982: 8: 235-242.

Zellweger C., Ammann M., Hofer P. and Baltensperger U. NOy speciation with a combined wet effluent diffusion denuder-aerosol collector coupled to ion chromatography. Atmos Environ 1999: 33: 1131-1140. 
Table 1. Location of school sampling sites relative to area freeways.

\begin{tabular}{|c|c|c|c|c|}
\hline School ID ${ }^{\mathrm{a}}$ & $\begin{array}{l}\text { Traffic } \\
\text { source }^{b}\end{array}$ & $\begin{array}{l}\text { AADT } \\
(\# / \text { day })^{\mathrm{b}}\end{array}$ & $\begin{array}{c}\text { Distance } \\
(\mathrm{m})^{\mathrm{c}}\end{array}$ & $\begin{array}{l}\text { Direction } \\
\text { of source }\end{array}$ \\
\hline \multicolumn{5}{|c|}{ Upwind of freeway } \\
\hline 4 & $\mathrm{I}-880$ & 210,000 & 1,700 & NE-E \\
\hline 7 & $\mathrm{I}-580$ & 130,000 & 1,500 & E \\
\hline 3 & $\mathrm{I}-880$ & 210,000 & 360 & NE-E \\
\hline 8 & $\mathrm{I}-580$ & 130,000 & 350 & E \\
\hline \multicolumn{5}{|c|}{ Downwind and close to freeway } \\
\hline $10^{\mathrm{d}}$ & $\mathrm{I}-880$ & 190,000 & $60^{\mathrm{e}}$ & SW \\
\hline 5 & $\mathrm{I}-880$ & 210,000 & $130^{\mathrm{e}}$ & SW-W \\
\hline 9 & $\mathrm{I}-880$ & 200,000 & 200 & SW-W \\
\hline $2^{f}$ & CA-92 & 90,000 & $230^{\mathrm{g}}$ & W-NW \\
\hline \multicolumn{5}{|c|}{ Downwind and far from freeway } \\
\hline 6 & $\mathrm{I}-880$ & 210,000 & 1,200 & SW-W \\
\hline 1 & I-880 & 210,000 & 1,400 & SW-W \\
\hline
\end{tabular}

\footnotetext{
${ }^{a}$ Assigned arbitrarily.

${ }^{\mathrm{b}}$ Includes roadways with annual average daily traffic (AADT) above 50,000 vehicles per day and located within $1000 \mathrm{~m}$ of school. AADT estimate provided by CA Dept of Transportation.

${ }^{\mathrm{c}}$ Distances measured using both geographical information system and scaled map.

${ }^{\mathrm{d}}$ Shopping center and parking lot abut school grounds to south and freeway off ramp located $<50$ $\mathrm{m}$ to northwest.

${ }^{\text {e }}$ Obtained with measurement wheel

${ }^{\mathrm{f}} \mathrm{I}-880$ located $390 \mathrm{~m}$ to east-northeast (school generally upwind of I-880).

${ }^{g}$ Distance confirmed from aerial photograph.
} 
Table 2. $\mathrm{NO}_{2}$ and $\mathrm{NO}_{\mathrm{X}}$ sampling periods.

\begin{tabular}{|c|c|c|c|c|c|c|}
\hline $\begin{array}{l}\text { Week } \\
\text { I.D. }\end{array}$ & Start Date & $\begin{array}{l}\text { Mean } \\
\text { Temp } \\
\left({ }^{\circ} \mathrm{C}\right) \\
\end{array}$ & $\begin{array}{c}\text { Mean wind } \\
\text { direction } \\
\left({ }^{\circ} \text { from } N\right) \\
\end{array}$ & $\begin{array}{c}\text { Mean wind } \\
\text { speed } \\
(\mathrm{m} / \mathrm{s})\end{array}$ & $\begin{array}{c}\mathrm{NO}_{2} \text { at } \\
\text { Fremont }^{\mathrm{a}} \\
(\mathrm{ppb}) \\
\end{array}$ & $\begin{array}{c}\mathrm{NO}_{\mathrm{X}} \text { at } \\
\text { Fremont }^{\mathrm{a}} \\
(\mathrm{ppb})\end{array}$ \\
\hline \multicolumn{7}{|c|}{ Spring 2002 monitoring at ten schools } \\
\hline 1 & $3 / 14 / 01$ & 16 & 239 & 3.6 & 23.5 & 38.6 \\
\hline $2^{\mathrm{b}}$ & $3 / 21 / 01$ & 16 & 246 & 4.3 & 14.7 & 19.9 \\
\hline 3 & $3 / 28 / 01$ & 14 & 239 & 5.1 & 15.7 & 28.5 \\
\hline 4 & $4 / 4 / 01$ & 12 & 247 & 5.9 & 15.1 & 24.7 \\
\hline $5^{\mathrm{c}}$ & $4 / 11 / 01$ & 14 & 232 & 4.7 & 16.6 & 26.7 \\
\hline 7 & $4 / 27 / 01$ & 14 & 274 & 5.0 & 12.3 & 15.3 \\
\hline 8 & $5 / 2 / 01$ & 16 & 243 & 4.3 & 25.1 & 39.9 \\
\hline 9 & $5 / 9 / 01$ & 23 & 272 & 4.9 & 16.7 & 22.6 \\
\hline $10^{\mathrm{d}}$ & $5 / 16 / 01$ & 18 & 281 & 4.0 & 23.4 & 32.6 \\
\hline $11^{\mathrm{c}}$ & $5 / 23 / 01$ & 20 & 261 & 4.8 & 17.1 & 25.3 \\
\hline 13 & $6 / 5 / 01$ & 18 & 255 & 5.2 & 12.1 & 18.3 \\
\hline 14 & $6 / 13 / 01$ & 20 & 282 & 4.1 & 25.3 & 41.1 \\
\hline \multicolumn{7}{|c|}{ Fall 2001 monitoring at ten schools } \\
\hline 15 & $9 / 26 / 01$ & 20 & 254 & 3.8 & 26.8 & 45.1 \\
\hline 16 & 10/3/01 & 17 & 249 & 4.1 & 18.0 & 30.2 \\
\hline 17 & 10/10/01 & 20 & 235 & 3.5 & 26.3 & 43.1 \\
\hline 18 & 10/17/01 & 16 & 225 & 3.5 & 25.1 & 50.4 \\
\hline 19 & $10 / 24 / 01$ & 17 & 221 & 3.7 & 25.2 & 50.1 \\
\hline 20 & $10 / 31 / 01$ & 15 & 212 & 3.2 & 27.1 & 64.4 \\
\hline 21 & $11 / 7 / 01$ & 16 & 176 & 3.8 & 29.9 & 54.6 \\
\hline 22 & 11/15/01 & 16 & 200 & 3.0 & 24.9 & 58.6 \\
\hline \multicolumn{7}{|c|}{ Spring 2002 neighborhood monitoring (includes ten schools) } \\
\hline 23 & 04/23/02 & 14 & 253 & 5.8 & 12.0 & 14.6 \\
\hline 24 & 05/02/02 & 16 & 252 & 5.2 & 12.3 & 17.4 \\
\hline
\end{tabular}

${ }^{\mathrm{a}}$ Fremont, CA monitoring station operated by Bay Area Air Quality Management District.

${ }^{\mathrm{b}}$ Both $\mathrm{NO}_{2}$ and $\mathrm{NO}_{\mathrm{X}}$ data disqualified because of apparent sample identity mix-up.

c Two-week sampling interval.

${ }^{\mathrm{d}} \mathrm{NO}_{2}$ and $\mathrm{NO}_{\mathrm{X}}$ data disqualified because of sample identity recording error. 
Table 3. Precision of passive samplers: results of LBNL analysis for 26 co-location events.

\begin{tabular}{ccccc}
\hline Compound & \multicolumn{2}{c}{$\begin{array}{c}\text { Measured concentrations } \\
(\mathrm{ppb})\end{array}$} & \multicolumn{2}{c}{$\begin{array}{c}\text { Relative deviations } \\
(\%)\end{array}$} \\
& Mean (SD) & Range & Mean (SD) & Range \\
\hline $\mathrm{NO}_{2}$ & $21(7)$ & $11-37$ & $3.1(2.2)$ & $0.7-10$ \\
$\mathrm{NO}_{\mathrm{X}}$ & $43(21)$ & $16-85$ & $4.2(2.7)$ & $0.2-7.5$ \\
$\left(\mathrm{NO}_{\mathrm{X}}-\mathrm{NO}_{2}\right)$ & $21(15)$ & $3.7-56$ & $9.7(8.5)$ & $1.0-36$ \\
\hline
\end{tabular}

Table 4. Summary of outdoor $\mathrm{NO}_{2}$ and $\mathrm{NO}_{\mathrm{X}}$ monitoring at ten school sites.

\begin{tabular}{|c|c|c|c|c|c|c|c|}
\hline \multirow[b]{2}{*}{ School } & \multirow[b]{2}{*}{$\mathrm{N}$} & \multicolumn{2}{|c|}{$\begin{array}{c}\text { Measured } \\
\text { concentrations } \\
(\mathrm{ppb}) \\
\text { Mean (SD) }\end{array}$} & \multicolumn{2}{|c|}{$\begin{array}{c}\text { Concentrations normalized } \\
\text { to Fremont } \\
\text { monitoring station } \\
\text { Mean (SE) }\end{array}$} & \multicolumn{2}{|c|}{$\begin{array}{c}\text { Schools with different } \\
\text { normalized concentrations } \\
\qquad(\mathrm{p}<0.05)\end{array}$} \\
\hline & & $\mathrm{NO}_{2}$ & $\mathrm{NO}_{\mathrm{X}}$ & $\mathrm{NO}_{2}$ & $\mathrm{NO}_{\mathrm{X}}$ & $\mathrm{NO}_{2}$ & $\mathrm{NO}_{\mathrm{X}}$ \\
\hline \multicolumn{8}{|c|}{ Upwind of freeway } \\
\hline 4 & 20 & $19(6)$ & 40 (19) & $\mathbf{0 . 9 1}(0.03)$ & $1.12(0.05)$ & $2,5,8-10$ & $2,5,9,10$ \\
\hline 7 & 19 & $20(5)$ & $31(10)$ & $1.01(0.04)$ & $0.92(0.05)$ & $2,5,9,10$ & $2,3,5,8-10$ \\
\hline 3 & 20 & $20(7)$ & $47(22)$ & $1.00(0.03)$ & $1.34(0.07)$ & $2,5,9,10$ & $5-7,9,10$ \\
\hline 8 & 20 & $23(6)$ & $42(16)$ & $1.14(0.06)$ & $1.23(0.06)$ & $4,5,9,10$ & $5,7,9,10$ \\
\hline \multicolumn{8}{|c|}{ Downwind and close to freeway } \\
\hline 10 & 19 & $30(5)$ & $65(18)$ & $1.62(0.10)$ & $2.07(0.16)$ & $1-9$ & $1-4,6-9$ \\
\hline 5 & 20 & $26(6)$ & $57(15)$ & $1.34(0.06)$ & $1.81(0.16)$ & $1,3,4,6-8,10$ & $1-4,6,7,8$ \\
\hline 9 & 19 & $26(5)$ & $55(18)$ & $1.34(0.08)$ & $1.64(0.11)$ & $1,3,4,6-8,10$ & $1,3,4,6-8,10$ \\
\hline 2 & 20 & $24(7)$ & $53(22)$ & $1.20(0.04)$ & $1.54(0.07)$ & $3,4,6,7,10$ & $1,4-7,10$ \\
\hline \multicolumn{8}{|c|}{ Downwind and far from freeway } \\
\hline 6 & 20 & $21(6)$ & $36(13)$ & $1.02(0.03)$ & $1.08(0.05)$ & $2,5,9,10$ & $2,3,5,9,10$ \\
\hline 1 & 20 & $21(6)$ & 40 (15) & $1.06(0.03)$ & $1.17(0.06)$ & $5,9,10$ & $2,5,9,10$ \\
\hline
\end{tabular}


Table 5. Summary of neighborhood $\mathrm{NO}_{2}$ and $\mathrm{NO}_{\mathrm{X}}$ monitoring.

\begin{tabular}{|c|c|c|}
\hline \multirow{2}{*}{ Monitoring location } & \multicolumn{2}{|c|}{ Concentrations (ppb) } \\
\hline & $\mathrm{NO}_{2}$ & $\mathrm{NO}_{\mathrm{X}}$ \\
\hline \multicolumn{3}{|l|}{ School 3} \\
\hline Residence mean $(n=13)$ & 10.9 & 18.8 \\
\hline Residence median $(\mathrm{n}=13)$ & 10.3 & 17.4 \\
\hline School site $(n=2)$ & 10.6 & 17.3 \\
\hline \multicolumn{3}{|l|}{ School 5} \\
\hline Residence $^{a}$ mean $(n=13)$ & 17.5 & 29.1 \\
\hline Residence $^{\mathrm{a}}$ median $(\mathrm{n}=13)$ & 17.5 & 26.0 \\
\hline School site $(n=2)$ & 23.1 & 36.2 \\
\hline \multicolumn{3}{|l|}{ School 6} \\
\hline Residence mean $(n=16)$ & 15.0 & 22.5 \\
\hline Residence median $(\mathrm{n}=16)$ & 15.1 & 20.7 \\
\hline School site $(\mathrm{n}=3)$ & 13.6 & 17.8 \\
\hline
\end{tabular}

${ }^{\mathrm{a}}$ Includes one nearby school.

\section{Figure Captions}

Figure 1. Mean wind direction by month at Oakland International and Hayward Executive airports (June 2000 through May 2002). 270 = wind originating from the west.

Figure 2. Results of one-week co-located measurements of $\mathrm{NO}_{2}$ and $\mathrm{NO}_{\mathrm{X}}$ using passive samplers deployed on roof of Bay Area Air Quality Management District monitoring station in Fremont, CA. Chemiluminescence results provided by BAAQMD.

Figure 3. Outdoor $\mathrm{NO}_{2}$ concentrations at 10 schools. Horizontal lines indicate $10^{\text {th }}, 25^{\text {th }}, 50^{\text {th }}$, $75^{\text {th }}$, and $90^{\text {th }}$ percentiles; circles represent points below $10^{\text {th }}$ and above $90^{\text {th }}$ percentile.

Figure 4. Outdoor $\mathrm{NO}_{\mathrm{X}}$ concentrations at 10 schools. See Figure 3 for definition of symbols.

Figure 5. $\mathrm{NO}_{2}$ and $\mathrm{NO}_{\mathrm{X}}$ concentrations at 10 schools normalized to values measured at Fremont station. Values are mean \pm 1 standard error from 18 one-week and 2 two-week measurement periods. Legend indicates freeway closest to each school. 
Figure 6. Neighborhood study results: $\mathrm{NO}_{2}$ and $\mathrm{NO}_{\mathrm{X}}$ outside residences of students attending three study schools. See Figure 3 for definition of symbols. Not shown is a measurement of 70 ppb $\mathrm{NO}_{\mathrm{X}}$ at a residence adjacent to I-880.

Figure 7. $\mathrm{NO}_{2}$ and $\mathrm{NO}_{\mathrm{X}}$ concentrations outside residences of students attending schools 3 and 5. Predominant wind direction was from the west and southwest, perpendicular to I-880.

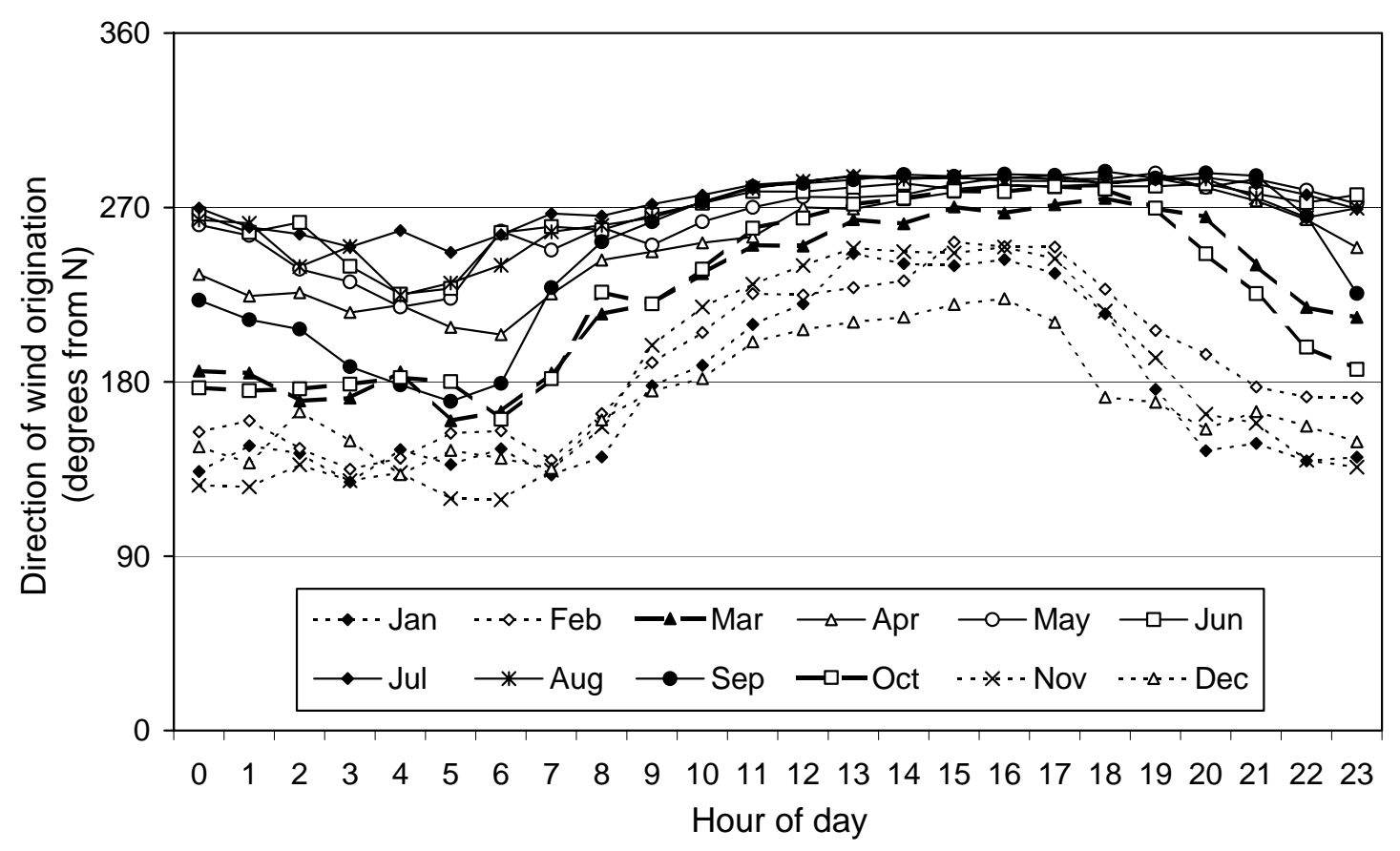

Figure 1 


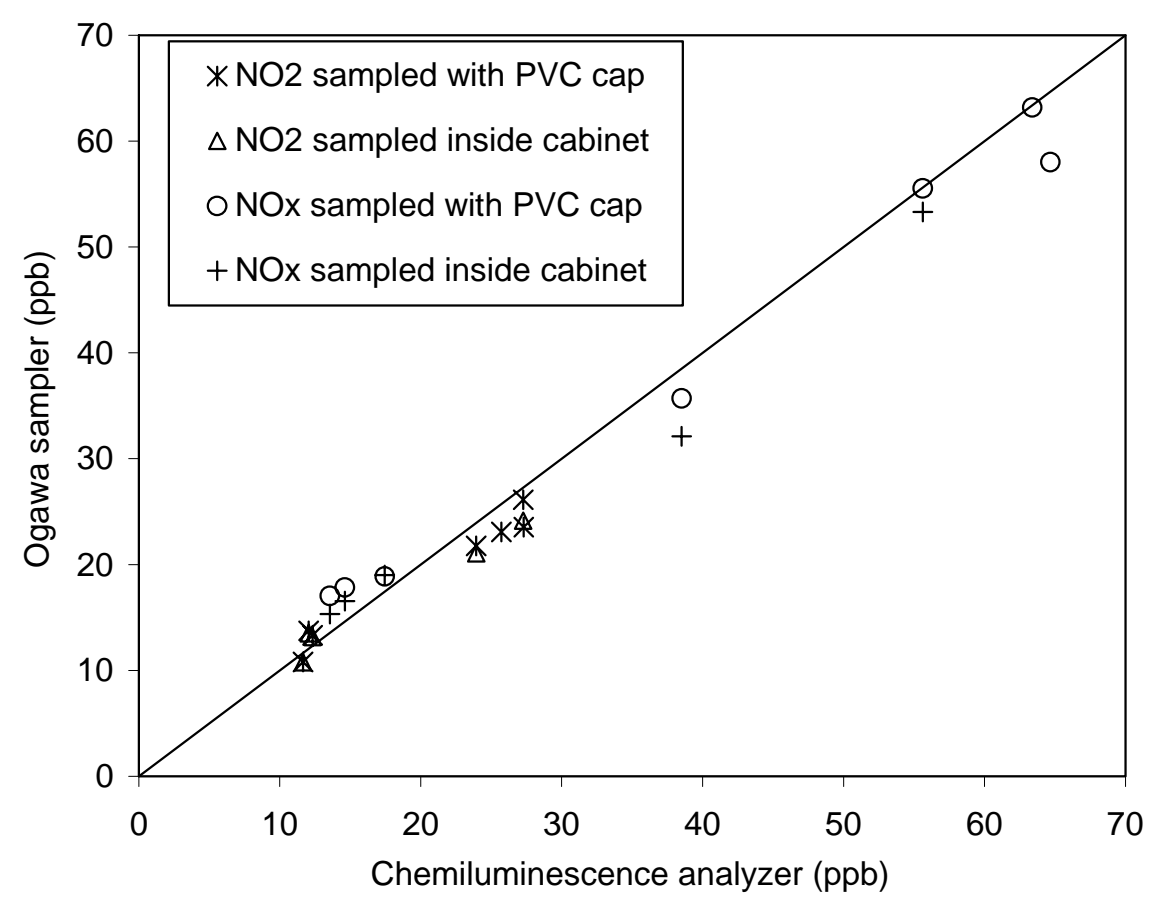

Figure 2

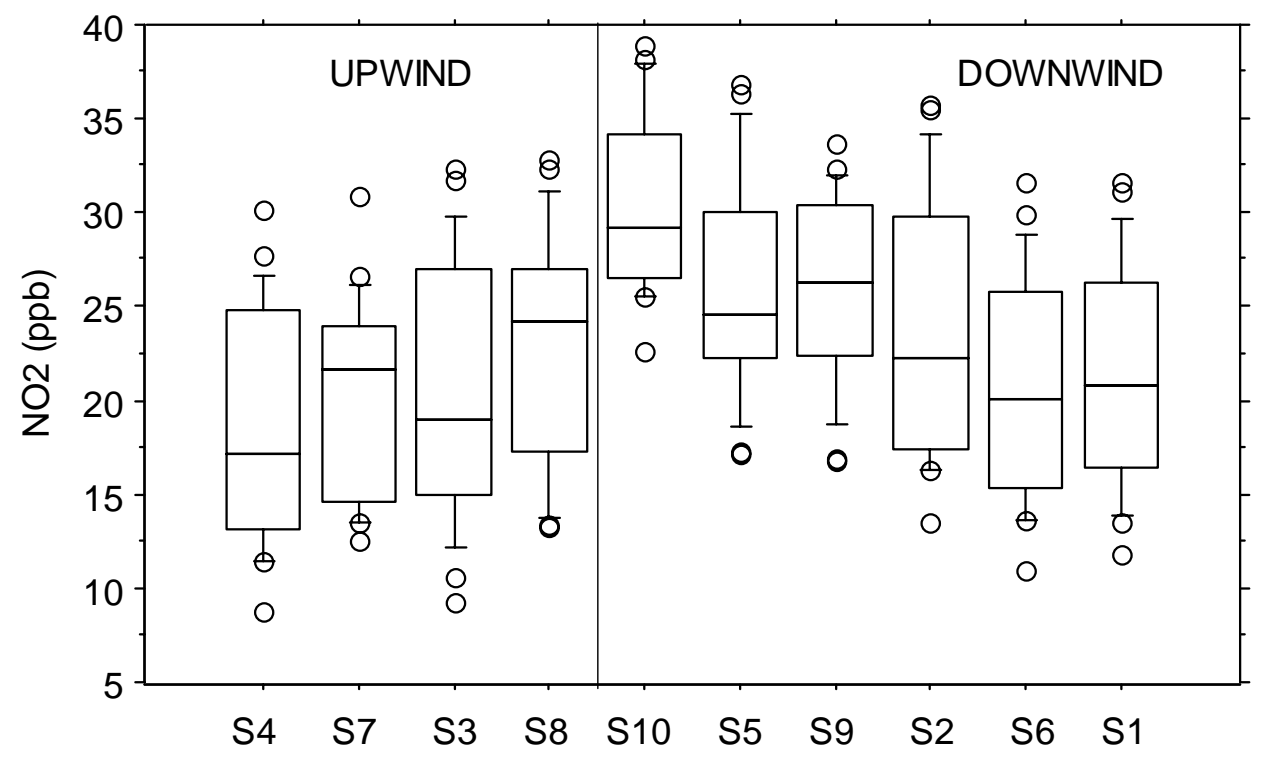

Figure 3 
Singer et al., Passive NOx FINAL

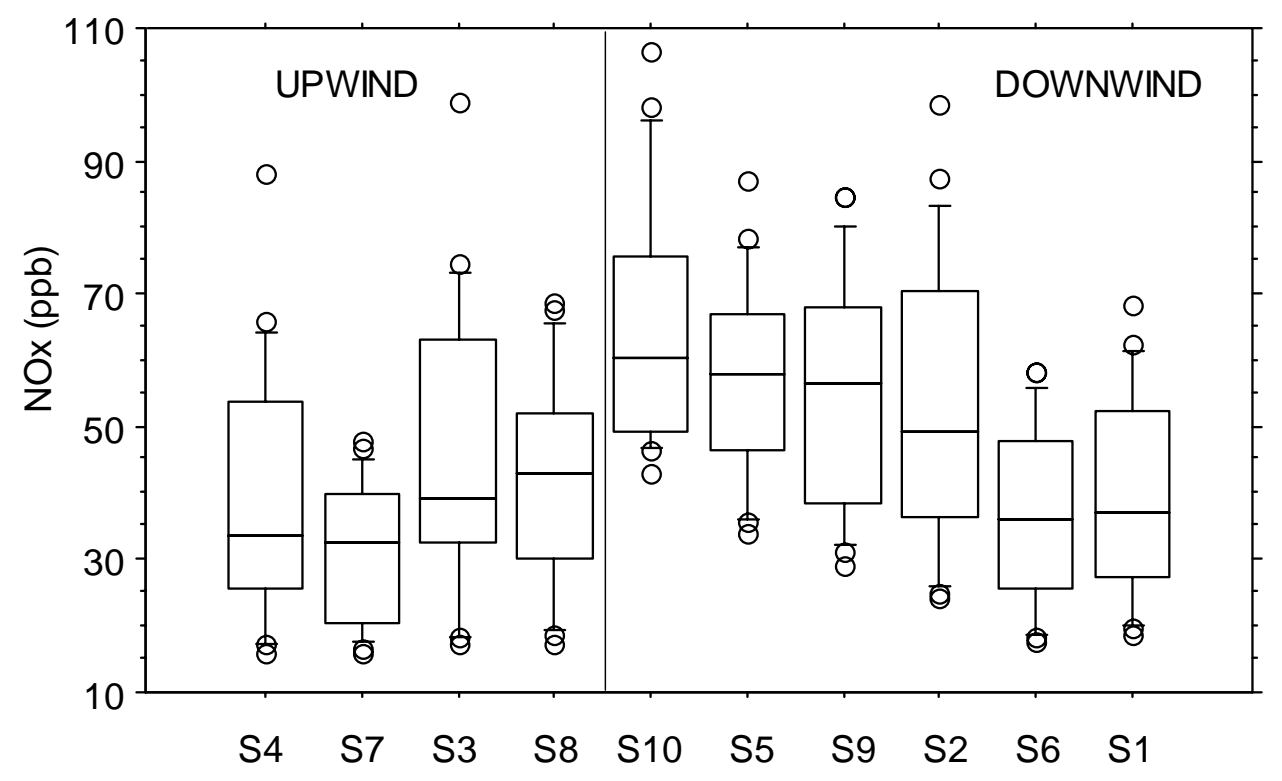

Figure 4
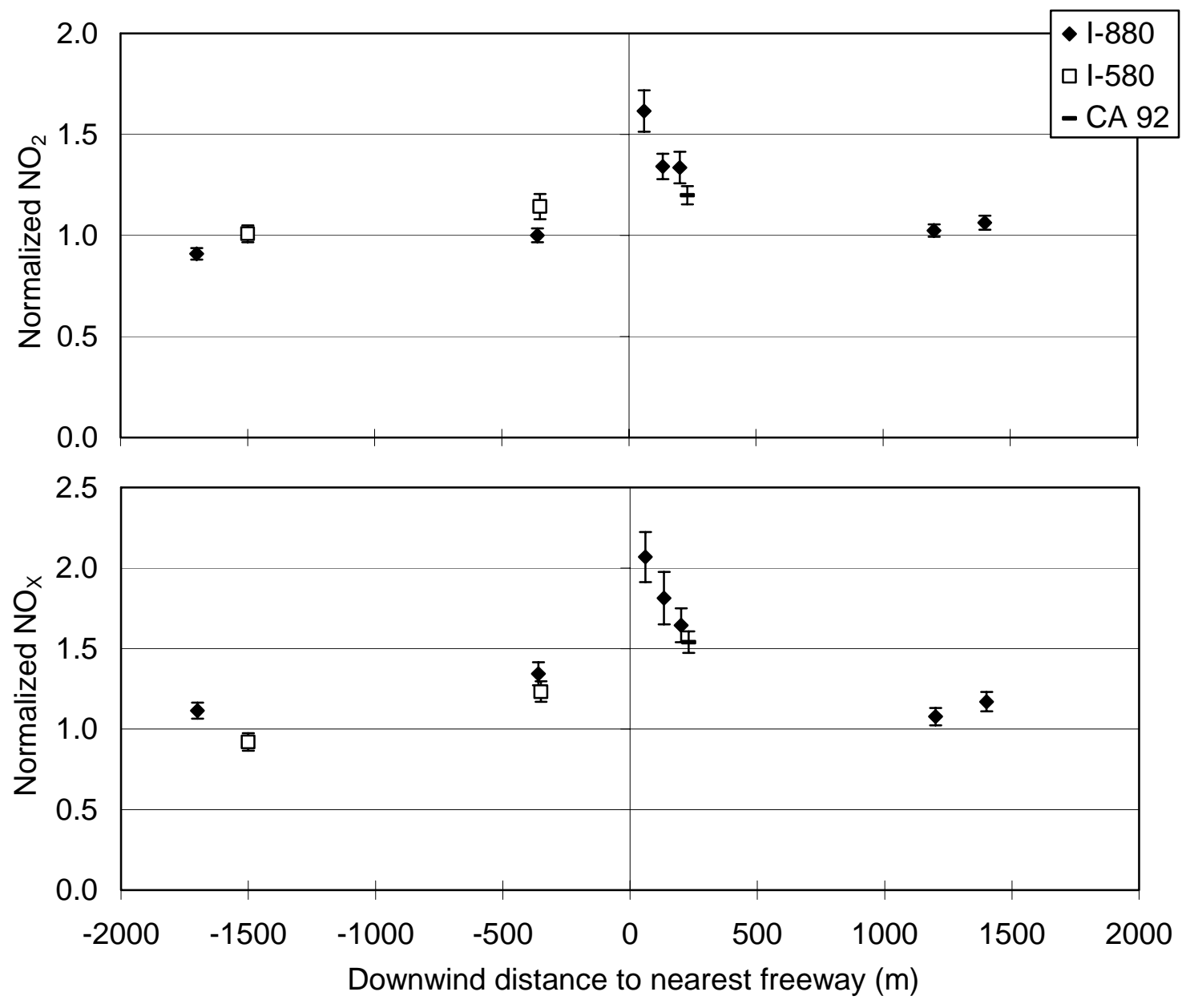

Figure 5 


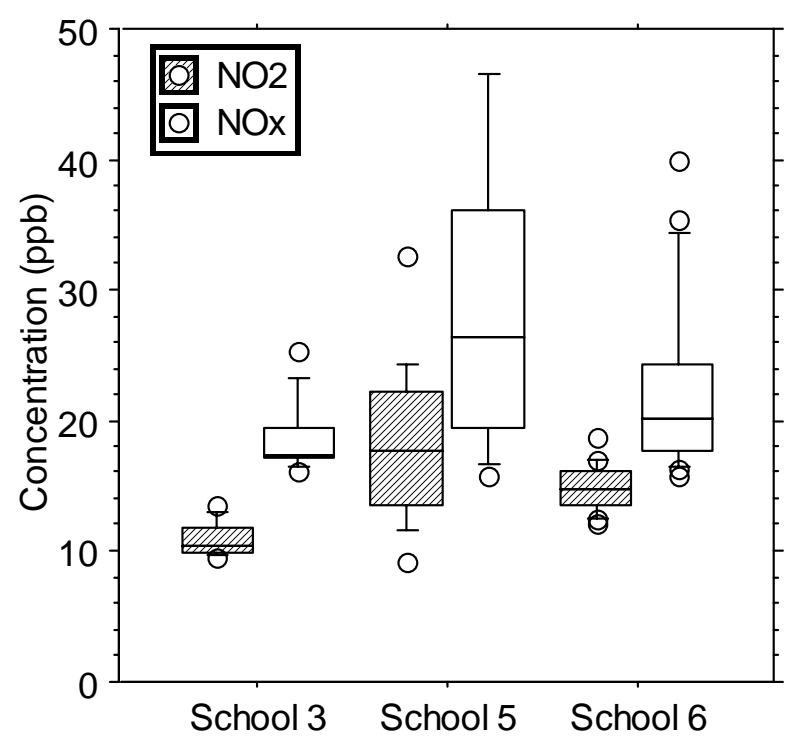

Figure 6
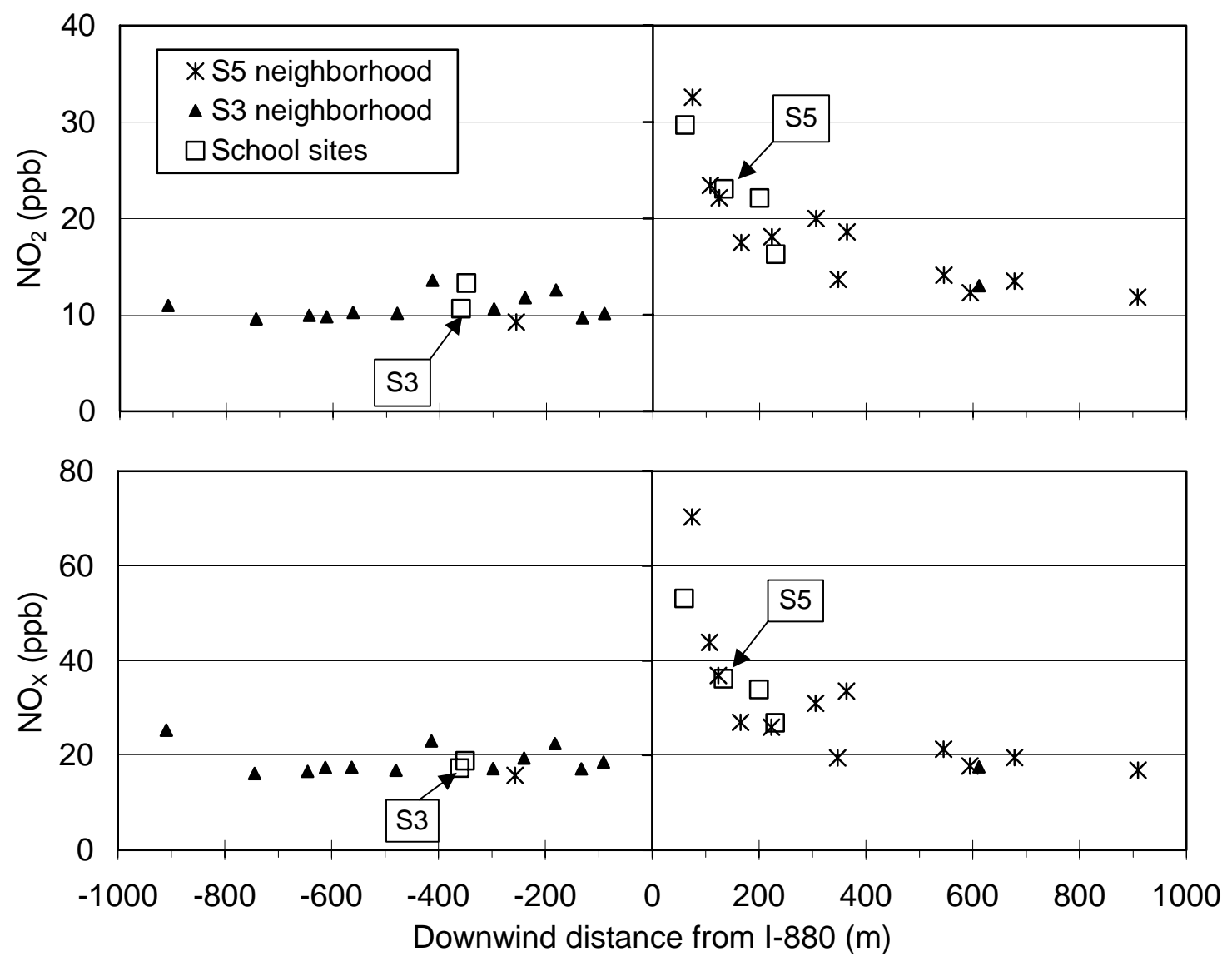

Figure 7 